\title{
The Expansion Path and Strategy of Mobile Shopping User Group based on Customer Cognition and Customer Emotion
}

\author{
He Qiuyan \\ School of Management \\ Wuhan University of Technology \\ Wuhan China \\ e-mail: 1551781302@qq.com
}

\author{
Li Daoyi \\ School of Management \\ Wuhan University of Technology \\ Wuhan China \\ e-mail: 358040251@qq.com
}

\begin{abstract}
In the era of the user is king, expanding the user base of mobile shopping has become a business access to key first-mover advantage. Only through the good emotional reaction of the customer's mobile shopping process could we convert customer cognition to use intention of mobile shopping. This paper analyzes the influence path of customer cognition on the use intention of mobile shopping to propose the user expansion path of mobile shopping. Thus, proposes mobile shopping user expansion path from the customer cognition and customer emotion, in order to provide information and reference for the business practices.
\end{abstract}

Keywords-mobile shopping; customer cognition; customer emotion; competitive advantage; expansion path

\section{INTRODUCTION}

Mobile Internet has entered a period of explosive growth, which has a broad development prospects. Mobile shopping market as a new gap in the market, has begun to compete with major businesses. The number of users is related to the enterprise's ability to seize the initiative of the mobile shopping market in the big data era. And customer emotion can predict people's behavior intention, and the accumulation of positive customer's emotion can promote the continuous purchase and customer loyalty. Therefore, the mobile business enterprise pay attention to customer sentiment as the entry point to promote mobile shopping intention, is essential for the enterprise to quickly capture the market, get ahead of the edge. Based on the research hypothesis and the concept model, this paper put forward the path and strategy of mobile shopping user group in the impact of customer cognition and customer emotion which provides information and reference for mobile shopping business.

On the basis of the research of customer cognition, customer emotions and customers use intention theories, in conjunction with mobile shopping background, the paper presents five assumptions about the relationship between the three, and use the method of questionnaire to carry out the empirical test.The empirical results shown in Fig.1.

\section{THEORY AND HYPOTHESES}

On the basis of the research of customer cognition, customer emotions and customers use intention theories, in conjunction with mobile shopping background, the paper presents five assumptions about the relationship between the three, and use the method of questionnaire to carry out the empirical test.The empirical results shown in Fig.1.

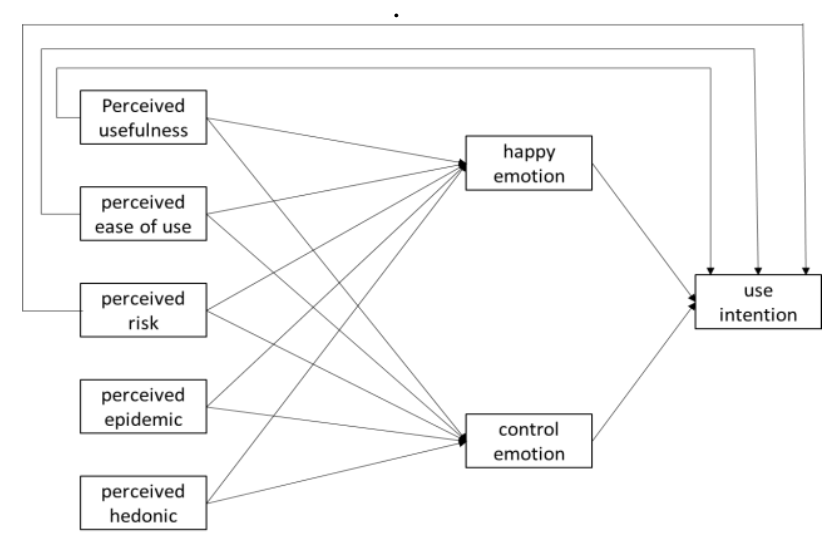

Figure 1. Relationship of customer cognition, customer emotions and use intentions of mobile shopping

In order to show the customer cognition of the influence path of use intention of mobile shopping more clearly and accurately, Figure 2-1 will be decomposed into Figure 2,3,4,5,6.And the dotted line represents the indirect path, the solid line shows the direct path. Obviously, the influence path of customer cognition on the use intention of mobile shopping are a total of 13. Among them, the direct influence path only three ( P2, P5 and P8). The remaining 10 are indirect influence path, the each dimension of which are need of customer emotion to further influence the use intention of mobile shopping.

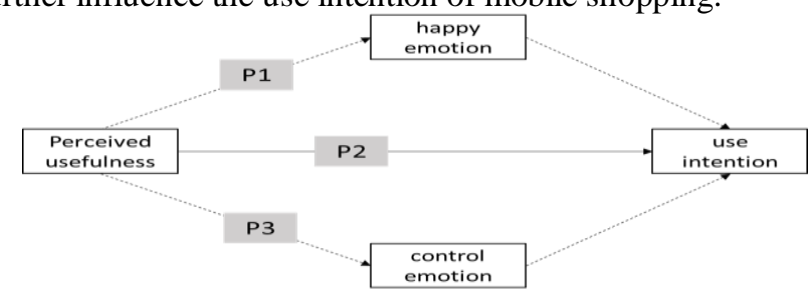

Figure 2. the influence path of perceived usefulness on use intention

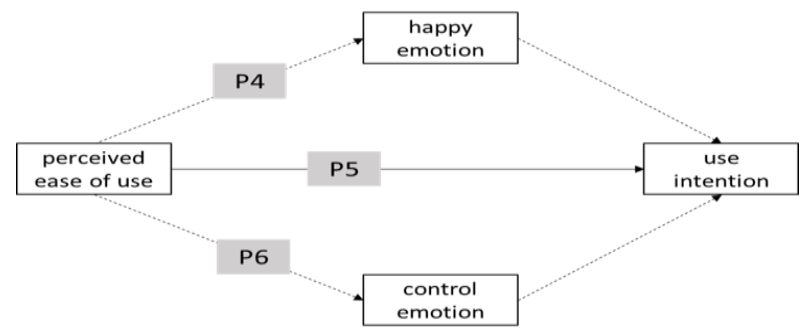

Figure 3. the influence path of perceived ease of use on use intention 


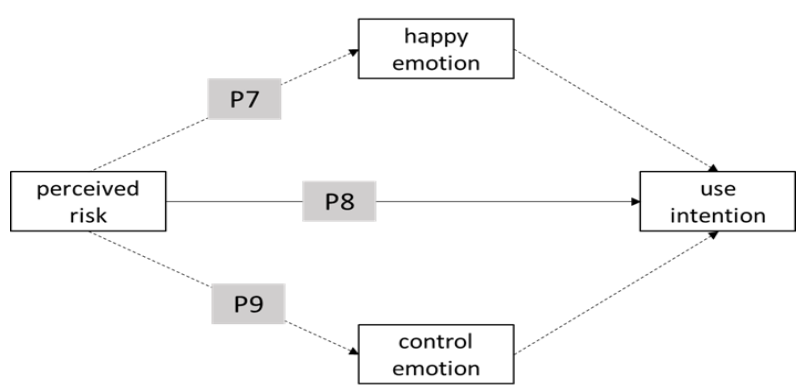

Figure 4. the influence path of perceived ease of use on use intention

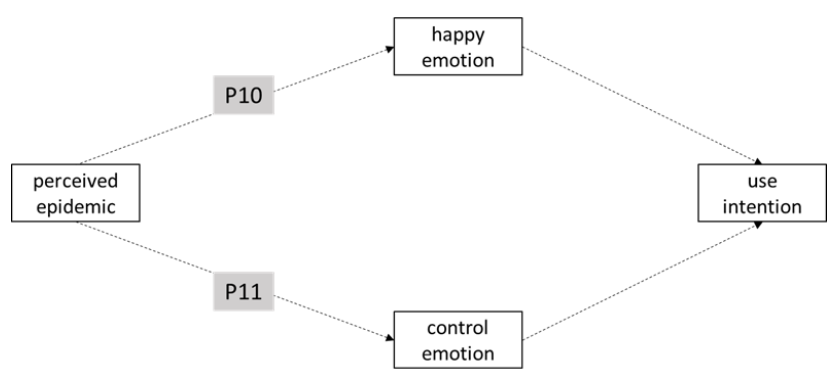

Figure 5. the influence path of perceived epidemic on use intention

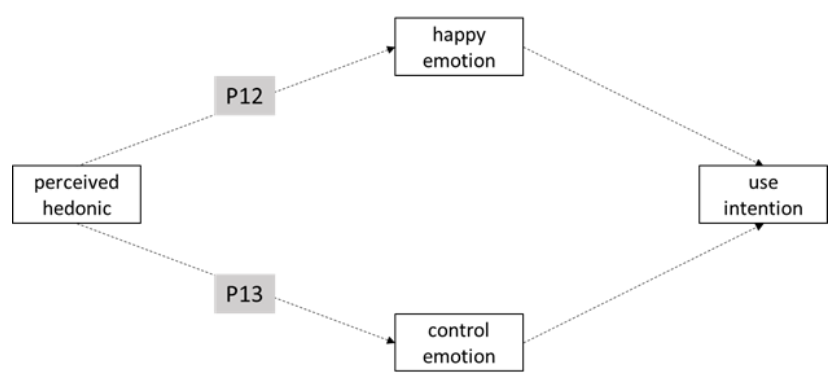

Figure 6. the influence path of perceived hedonic on use intention

From the path analysis above, the happy emotion and control emotion plays an crucial intermediary role to the intention use of mobile shopping. Only by good emotion reaction in the mobile shopping process could we convert customer cognition to use intention better. Thus, the mobile business enterprise must design product information on the purpose of foster positive customer emotion in order to expand the mobile shopping user groups better, with positive cognitive elements to drive positive customer emotional response, including positive happy emotions and positive controls emotions, to prompt use intention of mobile shopping to produce, and thus the use the mobile shopping.

\section{MOBILE SHOPPING USER GROUP EXPANSION PATH}

Based on the analysis of influence path, this paper puts forward user group expansion path of mobile shopping (Figure 7). Because the influence of customer cognition on mobile shopping use intention include direct influence and indirect influence Therefore, enterprises also have two main path to expand mobile shopping user group, and the starting point are both effectively designed by related cognition information, the end are both to achieve to expand the user group expansion.
The first path is: enterprise make reasonable and usefulness design for perceived usefulness perceived ease of use and perceived risk of mobile shopping products (direct influence path), to make customers form a good cognition of perceived usefulness perceived ease of use and perceived risk of enterprise products through these stimuli processing and let it have a high perceived value, so as to promote the consumer mobile shopping use intention, and finally achieve the goal of user group expansion.

The second path is: enterprise make reasonable and usefulness design for perceived usefulness perceived ease of use perceived risk perceived epidemic and perceived hedonic indirect influence path), to make customers form a good cognition of perceived usefulness perceived ease of use perceived risk perceived epidemic and perceived hedonic of enterprise products. Through the cognitive drive, make the customer's happy emotion and the emotion control have the high positive tendency.so as to promote the consumer mobile shopping use intention, and finally achieve the goal of user group expansion.

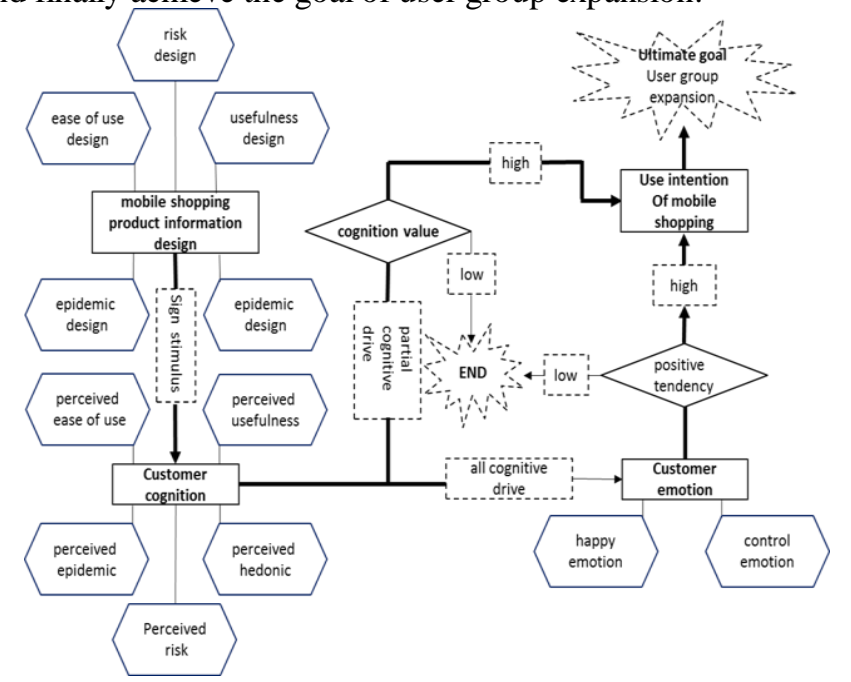

Figure 7. user group expansion of mobile shopping path

\section{MOBILE SHOPPING USER GROUP EXPANSION STRATEGY}

\section{A. User group expansion strategy in customer emotion level}

Empirical studies have confirmed the relationship between customer cognition, customer emotions and customer mobile shopping use intention, with a significant effect between any two variables namely, customer cognition and customer emotions both have a significant positive impact on mobile shopping customer use intention. Also, customer emotions and control emotions played a partial mediating role on the impact of customer cognition to mobile shopping use intention. Therefore, customer emotion plays a very important role in the process of influencing customer's intention to use mobile shopping that mobile business enterprise must focus attention, and take targeted strategies.

For mobile shopping, the influence of controlling emotion is more than that of happy emotion. In the process of mobile shopping, the control emotion can affect the customer's psychology, and then affect the behavior 
intention. And the multiple regression analysis of the customer's cognition and control emotion shows that perceived ease of use is the greatest impact on the control emotions. Secondly the second is the usefulness and perceived risk, and perceived popularity and perceived enjoyment are relatively small. Visible, to a greater extent, the control emotions of the customers are determined by the simple operation, the convenience of payment and so on. In addition, the other four factors will also promote the production of customer control emotions to a certain extent.

And whether it is perceived ease of use, perceived usefulness or perceived risk of strengthening, for mobile shopping, mainly through the optimization of services to achieve Including through the technical optimization and improvement to adjust the mobile client interface easy to provide timely online service consulting, rich product types to provide customers with a wide range of services, improve the risk prevention level of online payment and so on. In short, the mobile business enterprise must enhance the customer's control of emotion, and then produce the customer's mobile shopping intention, it is necessary to improve the degree of autonomy of product use, as far as possible not to make customers have a sense of coercion or restraint during use.

At the same time Enterprises must pay great attention to the design of the sense of enjoyment to enhance the customer happy emotion. For mobile shopping, it must be rich in the selection and design of the page content, for example, the design of some sign to win points, time spike and more, so that customers feel the excitement of the shopping process and sense of accomplishment, thereby producing happy emotions based perception of pleasure.

\section{B. User group expansion strategy in customer cognitive level}

Due to the intermediary role of customer emotion, the main way to cultivate customer emotion is to enhance the perception of customer perception of each dimension. According to the empirical results, perceived usefulness, perceived risk, perceived ease of use have a direct impact on the intention to use both direct and indirect impact of customer perception, that shows these factors have a positive impact on customer emotion. Perceived usefulness, perceived risk and perceived hedonic have a high degree of influence on the mobile shopping use intention. Therefore, the mobile business enterprise in the mobile shopping terminal product design must pay particular attention to the perceived usefulness, perceived risk and perceived enjoyment and other factors, which can promote the generation of positive customer emotion, and thus promote the use of mobile shopping

Mobile business enterprises need to enhance the usefulness of mobile shopping from two aspects, thereby enhancing the customer's perception of the usefulness of mobile shopping, on the one hand, making customer demand as the starting point, further optimize the product, the real usefulness of mobile shopping to play to the extreme, on the other hand, enterprises need to pay attention to the additional needs of customers to purchase demand, and guide customer demand and even tap the potential demand of customers, to achieve the purpose of indirect appeal to customers, thereby enhancing the possibility of customers moving shopping. Only as far as possible to make customers aware of the usefulness of mobile shopping products, including the ability to bring more convenient, efficient and personalized shopping experience, in order to better motivate and promote the use of mobile shopping.

With the change of people's consumption habits and consumer psychology, the concept of shopping is no longer just stay on the consumer, but gradually rise to enjoy the high. These factors have put forward a very high request to the mobile shopping enterprise. Therefore, to attract customers in the fragmentation of time, enterprises will be more to enhance the fun of customers to use mobile shopping products. Specifically, is to enhance the social and personalized mobile shopping, in product design, to join such as sign, shake, near to find and other features, so that mobile shopping products become more threedimensional, enhance the customer's sense of pleasure, but also further enhance customer stickiness.

At present, the perceived risk of mobile customers mainly includes two aspects, namely, privacy risk and property risk. Therefore, for the enterprise, it is mainly from the two levels to prevent the risk of mobile shopping. From the level of reducing privacy risk, enterprise on the one hand need to enhance the ability to protect mobile shopping platform, improve the technology to prevent hackers attacks, on the other hand need to improve the business credit line. From the level of reducing the risk of property, enterprise on the one hand need to try to select the visibility and reputation better third-party payment platform for cooperation, ensure the security of mobile payment link, on the other hand need to strengthen the business credit system management, improve the relevant system, to avoid the loss of customers due to the credibility of the business or personal privacy security

Mobile shopping enterprises can expand its popularity from three aspects, firstly, Enterprises can open up their own mobile communication community, and through the community to provide customers with the exchange of related services and consulting, increase the stickiness between customers and enterprises, secondly, business and pocket shopping guide enterprise cooperation, with the help of shopping guide platform to expand their own traffic, thirdly, enterprises could cooperate with the most epidemic platform such as Weibo and WeChat, through effective publicity and promotion, let more people understand the mobile shopping, improve the social effects of mobile terminals, and thus enhance the perceived popularity of customers.

Enterprises need to design mobile shopping applications and purchase process as far as possible to consider the convenience and simplicity, enhance the customer's perception of ease of use. Thus, in the functions and page design, enterprise cannot blindly pursue the amount of information, but to take the operation of the fine, the operation of the page and the process to streamline. On the one hand, simplifying in the design of the page, on the product line selection, distribution and image processing; on the other hand, in the process of design, as far as possible to improve the relationship between shopping and payment and fast, reduce the registration login and other complex payment links 


\section{CONCLUSIONS}

There are 13 influence path of customer cognition on the use intention of mobile shopping. Among them, the direct influence path is only 3 , which is perceived usefulness, perceived ease of use and perceived risk impact on the use of intention. The other is the indirect path, that is, the customer's emotion is very important in the influence of customer perception on the use intention. Therefore, there are two paths of enterprise to expand mobile shopping users, divided into direct path and indirect path, the core is to develop a positive customer emotion for the purpose of designing customer cognitive elements, with positive cognitive factors driving customer positive emotional reaction, and then to promote customer mobile shopping intention to produce.

Accordingly mobile shopping user group expansion strategy mainly includes the level of customer emotion and customer cognition level that control emotion promotion strategy happy emotion promotion strategy perceived usefulness promotion strategy perceived risk reduction strategy perceived epidemic expansion strategy and perceived ease of use promotion strategy. Enterprises only take the customer as the core, pay close attention to customer's cognition and emotion, then can carry on the expansion of the mobile shopping user group more effectively, and then obtain the competitive advantage.

\section{REFERENCES}

[1] Penz E, Hogg M K. The role of mixed emotions in consumer behaviour: Investigating ambivalence in consumers' experiences of approach-avoidance conflicts in online and offline settings [J]. European Journal of Marketing, 2011, 45(1/2): 104-132.

[2] Kim, Sang Hee. "A study on consumers' emotion expression and a salesperson's responses in service encounter: Verbal and nonverbal communication." Journal of Consumer Studies 16.2 (2005): 111146.

[3] Lim, Choong Hoon, Tywan G. Martin, and Dae Hee Kwak. "Examining television consumers of mixed martial arts: The relationship among risk taking, emotion, attitude, and actual sportmedia-consumption behavior." International Journal of Sport Communication 3.1 (2010): 49-63.

[4] Lin, Ingrid Y. "Evaluating a servicescape: the effect of cognition and emotion." International Journal of Hospitality Management 23.2 (2004): 163-178.

[5] Schoefer, Klaus, and Christine Ennew. "The impact of perceived justice on consumers' emotional responses to service complaint experiences." Journal of Services Marketing 19.5 (2005): 261-270.

[6] Markus, Hazel R., and Shinobu Kitayama. "Culture and the self: Implications for cognition, emotion, and motivation." Psychological review 98.2 (1991): 224.

[7] Lazarus, Richard S., and Craig A. Smith. "Knowledge and appraisal in the cognition-emotion relationship." Cognition \& Emotion 2.4 (1988): 281-300.

[8] Lewis, Marc D. "Cognition-emotion feedback and the selforganization of developmental paths." Human Development 38.2 (1995): 71-102.

[9] Teasdale, John D. "Multi-level theories of cognition-emotion relations." (1999).

[10] Floresco, Stan B. "The nucleus accumbens: an interface between cognition, emotion, and action." Annual review of psychology 66 (2015): 25-52.

[11] Marino, Lori, and Christina M. Colvin. "Thinking pigs: a comparative review of cognition, emotion, and personality in sus domesticus." (2015).

[12] Manfrinati, Andrea. "United we stand, divided we fall: Cognition, emotion, and the moral link between them." Behavioral and Brain Sciences 38 (2015): 29.

[13] MaRRoquíN, BRett, and Susan Nolen-Hoeksema. "Event Prediction and Affective Forecasting in Depressive Cognition: Using Emotion as Information About the Future." Journal of Social and Clinical Psychology 34.2 (2015): 117-134.

[14] Uddin, Lucina Q., et al. "Beyond the tripartite cognition-emotioninteroception model of the human insular cortex." Journal of cognitive neuroscience 26.1 (2014): 16-27.

[15] Cromheeke, Sofie, and Sven C. Mueller. "Probing emotional influences on cognitive control: an ALE meta-analysis of cognition emotion interactions." Brain Structure and Function 219.3 (2014): 995-1008. 